\title{
Manipulação de drenos mediastinais e pleurais: existe evidência científica?
}

Mediastinal and pleural drains handling: is there scientific evidence?

La manipulación de los drenajes pleurales y mediastinales: ¿existe evidencia científica?

\author{
Líscia Divana Carvalho Silva $^{1}$; Larissa Lira Brito ${ }^{2}$
}

\begin{abstract}
Resumo
Trata-se de uma revisão do tipo sistemática com o objetivo de verificar a existência de evidência científica na manipulação de drenos pleurais e mediastinais na cirurgia cardíaca. As seguintes etapas foram percorridas: estabelecimento da hipótese e objetivos; estabelecimento de critérios de inclusão e exclusão de artigo; definição das informações a serem extraídas dos artigos selecionados; análise dos resultados; discussão e apresentação dos resultados. Para a seleção dos artigos foram utilizadas duas bases de dados, a saber: Literatura Latino-Americana e do Caribe em Ciências da Saúde (LILACS/BIREME) e Medical Literature Analysis and Retrieval System Online (MEDLINE). Os critérios de inclusão dos artigos definidos, inicialmente, foram: artigos publicados em português, inglês e espanhol, no período compreendido entre 2001-2012; capítulos de livros sobre a temática, artigos publicados cuja metodologia adotada permitisse obter evidências (níveis 1, 2 ou 3), artigos que retratassem procedimentos, intervenções ou diretrizes sobre a temática. A amostra final desta revisão integrativa foi constituída de 06 artigos. Não se observou diferença significativa na produção de drenagem mediastinal quando os drenos foram rotineiramente ordenhados, despojados, ou não tinham nenhuma manipulação, os drenos mantiveram-se permeáveis. Parece que a ordenha manual ou milking ou a ordenha com pinça ou stripping de drenos torácicos como rotina básica deve ser evitada. Não há estudos suficientes que comparem diferentes métodos de manipulação de drenos torácicos para apoiar ou não a eficácia relativa dos vários métodos. Nenhuma evidência de fato que seja clara e universal foi encontrada sobre a necessidade de manipulação de drenos.
\end{abstract}

Descritores: Cirurgia Torácica. Enfermagem. Assistência. Drenagem

\section{Abstract}

This is a review of the systematic type in order to verify the existence of scientific evidence in the handling of pleural and mediastinal drains in cardiac surgery. The following steps were followed: establishment of hypothesis and objectives; establishment of criteria for inclusion and exclusion article; definition of the information to be extracted from selected articles; analyzing the results; discussion and presentation of results. For the selection of the articles were used two databases, namely: Latin American and Caribbean Health Sciences (LILACS/BIREME) and Medical Literature Analysis and Retrieval System Online (MEDLINE). The inclusion criteria of definite articles initially were articles published in Portuguese, English and Spanish, in the period 20012012; book chapters on the subject, published articles whose methodology allowed to obtain evidence (levels 1,2 or 3), articles which reflect procedures, procedures or guidelines on the

\footnotetext{
${ }^{1}$ Enfermeira. Doutora em Ciências pela Escola de Enfermagem de Ribeirão Preto da Universidade de São Paulo (EERP-USP). Professora Adjunta I do Departamento de Enfermagem da Universidade Federal do Maranhão (UFMA). Avenida dos Portugueses, 1966. Campus. Bairro: Bacanga, São Luís - MA, Brasil. CEP: 65080805. E-mail: liscia@elo.com.br

${ }^{2}$ Enfermeira. Especialista em Cardiologia na Modalidade de Residência Multiprofissional do Hospital Universitário da Universidade Federal do Maranhão (HUUFMA). Avenida dos Portugueses, 1966. Campus. Bairro: Bacanga, São Luís- MA, Brasil. CEP: 65080805. E-mail: larissalbrito@hotmail.com
} 
subject. The final sample of this integrative review consisted of 6 articles. There was no significant difference in the production of mediastinal drainage when the drains were routinely milked, dispossessed or had no manipulation, the drains remained permeable. It seems that hand milking or milking or milking with tweezers or stripping chest tubes as basic routine should be avoided. There are not enough studies comparing different methods of handling chest tubes to support or not the relative effectiveness of various methods. No evidence of fact that is clear and universal was found on the need for handling drains.

Key-words: Thoracic Surgery. Nursing. Assistance. Drainage

\section{Resumen}

Esta es una revisión de tipo sistemática con el fin de verificar la existencia de evidencia científica en la manipulación y mediastínica drenaje pleural en cirugía cardíaca. Los siguientes pasos: establecimiento de la hipótesis y objetivos; establecimiento de criterios de inclusión y exclusión del artículo; definición de la información se extrae de los artículos seleccionados; Análisis de los resultados; discusión y presentación de los resultados. Para la selección de los artículos hemos utilizado dos bases de datos, a saber: la literatura latinoamericana y Caribbean Health Sciences (LILACS/BIREME) y Medical Literature Analysis y sistema de recuperación en línea (MEDLINE). Los criterios para la inclusión de artículos definidos, inicialmente, fueron: artículos publicados en Portugués, Inglés y español, en el período 2001-2012; capítulos de libros sobre el tema, los artículos publicados, cuya metodología adoptada permitieron obtener pruebas artículos (niveles 1, 2 o 3), que representa a los procedimientos, asistencia u orientación sobre el tema. La muestra final de esta revisión integral se compone de 6 artículos. Ninguna diferencia significativa se observó en la producción de drenaje mediastínico cuando los drenes se ordeñaron rutinariamente, desnudaron o no tenían ninguna manipulación, los drenes fueron permeables. Parece que la mano de ordeño u ordeño con pinzas o desmontaje de tubos torácicos como rutina básica debeevitarse. No hay no hay suficientes estudios que comparan diferentes métodos de manipulación de tubos torácicos para apoyar o no la efectividad relativa de varios métodos. No del hecho de que es clara y universal se encontraron pruebas acerca de la necesidad para la manipulación de los drenajes.

Palabras-claves: Cirugía Torácica, Enfermería, Asistencia, Drenaje.

\section{Introdução}

Há alguns anos, o tratamento dos problemas cardiovasculares vem obtendo avanços terapêuticos, clínicos e cirúrgicos. A opção pela intervenção cirúrgica ocorre quando se constata uma maior probabilidade de obtenção de vida útil. Este procedimento implica em alterações fisiológicas e impõe um grande estresse orgânico ${ }^{1}$.

A cirurgia cardíaca é um procedimento complexo que tem importantes repercussões orgânicas e pode ser do tipo reconstrutora, corretora, plástica ou substitutiva. As cirurgias reconstrutoras incluem a revascularização do miocárdio e a reconstrução das válvulas e as substitutivas são as cirurgias valvulares e os transplantes ${ }^{2,3}$.

As cirurgias cardíacas são realizadas em sua maioria por via esternotomia mediana, sendo 
ISSN 2179-6750

realizada a instalação de drenos pericárdicos e mediastinais objetivando a redução de sangue e líquido acumulados, evitando-se complicações pós-operatórias como o tamponamento cardíaco, derrame pericárdico e derrame pleural ${ }^{4}$. Na ocorrência de derrame pericárdico no pós-operatório, o aumento da pressão intracardíaca, decorrente do acúmulo de líquidos, o que pode levar à limitação do enchimento diastólico ventricular e a diminuição do débito cardíaco, caracterizando o tamponamento cardíaco. Os drenos torácicos, mediastinal ou pleural, são instalados pelo cirugião sob anestesia antes do término da cirurgia ou na Unidade de Terapia Intensiva (UTI) de maneira preventiva ou na presença de intercorrências ${ }^{5,6}$.

Os drenos instalados devem permanecer permeáveis permitindo o fluxo de fluídos livremente. Além de aspirações baixas e contínuas aplicadas aos drenos, estes podem ser manipulados a fim de melhorar a drenagem dos fluídos e evitar a formação de coágulos no sistema de drenagem ${ }^{7}$. Um dos objetivos principais a serem alcançados no cuidado de pacientes com drenos é a manutenção do sistema permeável, hermético e estéril, evitando a introdução de bactérias para o espaço intrapleural. A atenção constante para manter a permeabilidade do tubo facilita a expansão imediata do pulmão e minimiza as complicações ${ }^{8,9}$. Alguns métodos de manipulação utilizados para manter o sistema de drenagem permeável são a ordenha manual ou milking, a ordenha com pinça ou stripping, dobraduras ou fanfolding e percussão ou batidas ou tapping ${ }^{5}$. As técnicas de ordenha tem o propósito de desalojar a formação de coágulos por causarem um aumento temporário de sucção dentro da tubulação ${ }^{8}$.

A ordenha manual ou milking envolve manipulações como apertar, torcer, ou amassar para criar rajadas de sucção fazendo que os coágulos se movam. A ordenha com pinça na prática ou stripping significa geralmente comprimir o tubo torácico com o polegar ou o dedo indicador e, com a outra mão, puxar o tubo com a pinça usando um movimento para baixo do tubo adjacente ao tórax ${ }^{9}$. A ordenha manual, com pinça e métodos de dobraduras aumentam a pressão negativa do sistema e parece haver melhora na capacidade de remoção das drenagens e de coágulos, entretanto, pode aumentar a pressão negativa sendo prejudicial.

Acredita-se que o aumento das pressões intratorácicas possa prejudicar a função ventricular esquerda. Outra preocupação é sobre o uso indiscriminado do "clamp", também conhecido como "braçadeira". A oclusão temporária do sistema de drenagem contribue para um maior acúmulo de coágulos sanguíneos ${ }^{10}$, já que a braçadeira também é utilizada para realizar a ordenha em alguns serviços.

A incorreta manipulação do dreno de tórax pode acarretar uma série de complicações que podem resultar em um aumento da morbidade, prolongamento da hospitalização e, em alguns casos, 
ISSN 2179-6750

a morte. As complicações são mais prováveis de ocorrer se o dreno for manipulado por profissionais sem o conhecimento e ou habilidades adequadas. É muito importante que o cuidado ao paciente com dreno torácico seja embasado em evidência científica a fim de prevenir potenciais complicações e promover a segurança do paciente ${ }^{11}$.

As opniões atuais relacionadas as rotinas de manipulação de drenos, como a ordenha e suas variações, não são claramente indicadas, pois as mesmas têm potencial para aumentar as pressões intratorácicas, causando aprisionamento de tecidos no interior das tubulações, podendo aumentar potencialmente as hemorragias. Parece não existir uniformidade ou evidência comprovada sobre as formas de manipulações dos drenos, principalmente nos tipos de ordenha, nos métodos mais eficazes ou menos prejudiciais, nos períodos de manipulação, na rotina, na presença de um coágulo, no tamanho da tubulação e sobre seus efeitos colaterais ${ }^{5}$. Existe uma falta de concenso sobre os grandes princípios de gestão de drenos torácicos, dos quais está incluída a ordenha de drenos. Muitas decisões tendem a ser baseadas em fatores pessoais ao invés de evidências clínicas. Esta inconstência de regimes de tratamento, juntamente com a falta de evidências quanto aos cuidados de enfermagem cria uma incerteza geral quanto ao cuidado a esses pacientes ${ }^{12}$.

A instalação de drenos pericárdicos e mediastinais nas cirurgias cardíacas objetiva a redução de sangue e líquido acumulados, evitando-se complicações pós-operatórias como o tamponamento cardíaco, derrame pericárdico e derrame pleural ${ }^{4}$. Na ocorrência de derrame pericárdico no pósoperatório, o aumento da pressão intracardíaca, decorrente do acúmulo de líquidos, pode levar à limitação do enchimento diastólico ventricular e a diminuição do débito cardíaco. Assim, a pergunta clínica formulada para o alcance do objetivo proposto foi: A ordenha é eficaz para manutenção da permeabilidade dos drenos. Assim, o objetivo desta pesquisa foi verificar a eficácia da manipulação de drenos pleurais e mediastinais na cirurgia cardíaca.

\section{Método}

Trata-se de uma revisão de literatura sistemática sobre ordenha de drenos no pós-operatório de cirurgia cardíaca. A pesquisa foi realizada em bases de dados especializados disponíveis para acesso em sites, englobando artigos científicos, monografias, dissertações, opinião de especialistas e teses com data de publicação a partir do ano de 2001 indexados nessas bases. As publicações selecionadas para este estudo preencheram os seguintes critérios de inclusão: trabalhos obtidos na íntegra em português, inglês e espanhol; que continham informações sobre gerenciamento, cuidados e práticas com drenos pleurais e mediastinais que de alguma forma citaram sobre a ordenha de drenos. 
ISSN 2179-6750

A busca foi realizada nas seguintes bases de dados: Literatura Latino-Americana e do Caribe em Ciências da Saúde (LILACS/BIREME); Medical Literature Analysis and Retrieval System Online (MEDLINE). Durante a seleção, alguns artigos foram excluídos após a leitura dos resumos, por não se enquadrarem nos critérios de inclusão propostos, outros foram selecionados e excluídos após a leitura do artigo na íntegra, também por não estarem de acordo com os critérios previamente estabelecidos.

A outra fonte utilizada foi checar as referências bibliográficas dos estudos selecionados na busca realizada nas bases de dados eletrônicas, a fim de averiguar se todos os estudos foram localizados. Foram encontrados um total de 30 estudos, com a leitura dos resumos, enquadraram-se 15 artigos, após a leitura dos artigos na íntegra, excluindo-se os estudos duplicados e publicados em duplicidade de idiomas, a amostra foi constituída de 6 estudos que atenderam a proposta da presente revisão. Os estudos foram selecionados pela leitura do resumo e na ausência deste pelo título. Todo o material bibliográfico levantado foi analisado da seguinte forma: leitura crítica, enquadramento nos critérios de inclusão, fichamento com seleção dos dados mais relevantes e interpretação dos dados, conforme se segue no fluxograma abaixo:

Figura 1. Fluxograma de seleção de artigos

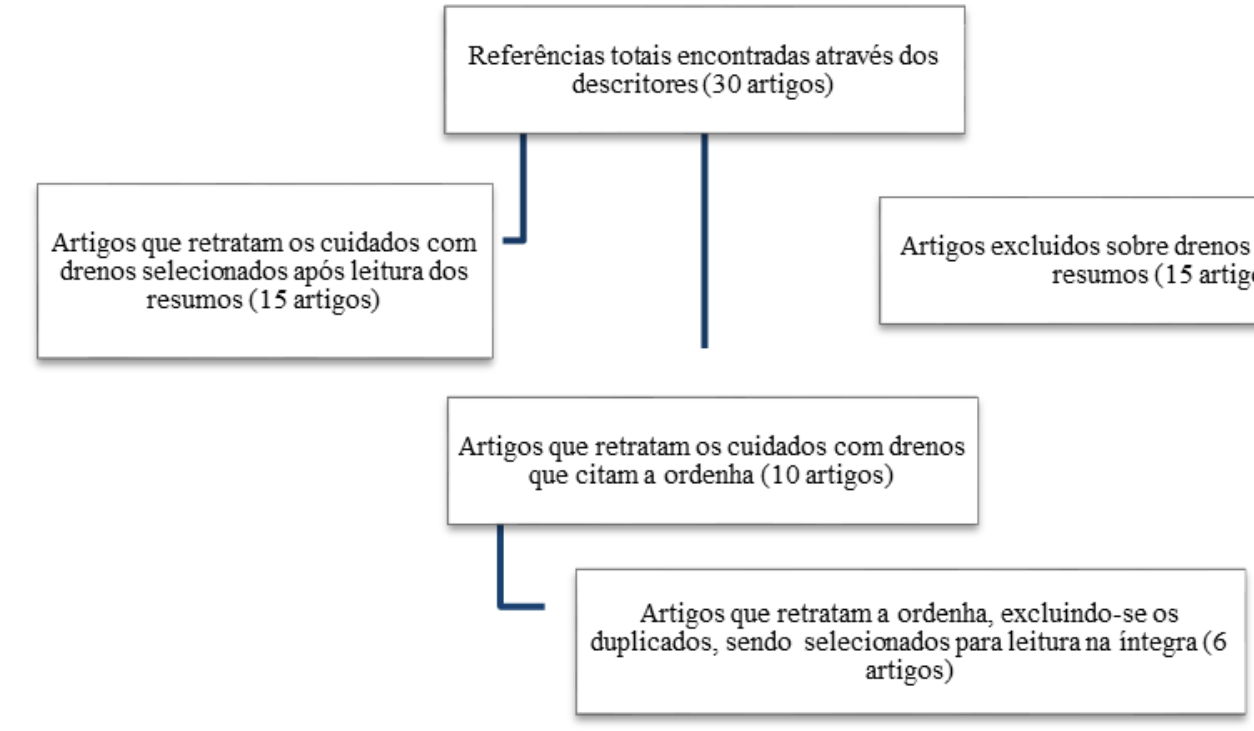

Fonte: Pesquisa Direta

As seguintes etapas foram percorridas: estabelecimento da hipótese e objetivos; estabelecimento de critérios de inclusão e exclusão de artigo; definição das informações a serem extraídas dos artigos selecionados; análise, discussão e apresentação dos resultados.

Esta pesquisa foi realizada de acordo com a Lei dos Direitos Autorais, que consiste na Lei ${ }^{\circ}$ 90 
ISSN 2179-6750

9.610 de fevereiro de 1998 (BRASIL, 1998). Sendo assim, o estudo foi devidamente conduzido no sentido de não plagiar quaisquer trabalhos, sempre realizando a citação de fontes e autoria e dispensando tratamentos adequados aos dados obtidos.

\section{Resultados e Discussão}

Para a análise e posterior síntese dos artigos que atenderam os critérios de inclusão, foi utilizado um quadro sinóptico, especialmente construído para esse fim, que contempla os seguintes aspectos: título do artigo e autor, objetivos, método, principais resultados e conclusão, conforme descritos e apresentados no quadro 1.

Quadro 1. Identificação dos artigos, segundo o título do artigo e autor, objetivos, delineamento do estudo, resultados e conclusão. (continua)

\begin{tabular}{|c|c|c|c|c|}
\hline $\begin{array}{c}\text { Título do artigo } \\
\text { e autor }\end{array}$ & Objetivos & $\begin{array}{l}\text { Delineamento } \\
\text { do estudo }\end{array}$ & Resultados & Conclusão \\
\hline $\begin{array}{l}\text { Mediastinal chest drain } \\
\text { clearance following } \\
\text { cardiac surgery. } \\
\text { Wallen et al. } 2009 .\end{array}$ & $\begin{array}{l}\text { Comparar os diferentes } \\
\text { métodos de desobstrução de } \\
\text { dreno torácico. }\end{array}$ & $\begin{array}{l}\text { Estudo com } \\
\text { ensaios } \\
\text { clínicos. }\end{array}$ & $\begin{array}{l}\text { Não há estudos suficientes para } \\
\text { comparação dos diferentes } \\
\text { métodos de desobstrução de } \\
\text { dreno torácico para apoiar uma } \\
\text { eficácia. Não houve diferença } \\
\text { nas evidências relacionadas. }\end{array}$ & $\begin{array}{l}\text { Não existem provas suficientes } \\
\text { para dizer se um método de } \\
\text { manipulação com a é melhor } \\
\text { que outro, ou que a } \\
\text { manipulação é necessária. }\end{array}$ \\
\hline $\begin{array}{l}\text { Nursing management of } \\
\text { chest drains: a systemic } \\
\text { review. } \\
\text { Charnock. Evans, } 2001 .\end{array}$ & $\begin{array}{l}\text { Resumir a melhor evidência } \\
\text { disponível relacionada com } \\
\text { gestão de enfermagem nos } \\
\text { drenos torácicos. }\end{array}$ & $\begin{array}{l}\text { Estudo } \\
\text { randomizado } \\
\text { controlado. }\end{array}$ & $\begin{array}{l}\text { Há evidências de pesquisa } \\
\text { limitadas a manutenção da } \\
\text { permeabilidade do tubo. A } \\
\text { ordenha manual ou com a pinça }\end{array}$ & $\begin{array}{l}\text { Atualmente, a gestão dos } \\
\text { sistemas de drenagem de tórax } \\
\text { é baseada na opinião de } \\
\text { especialistas com pouca } \\
\text { orientação disponíveis na } \\
\text { literatura. }\end{array}$ \\
\hline $\begin{array}{l}\text { To Strip or Notto Strip? } \\
\text { Physiological Effects of } \\
\text { Chest Tube Manipulation. } \\
\text { Margo,2007. }\end{array}$ & $\begin{array}{l}\text { Resumir a evidência } \\
\text { científica atual em relação às } \\
\text { seguintes questões clínicas: } \\
\text { A prática de ordenha manual } \\
\text { ou mecânica de drenos } \\
\text { torácicos aumentam a } \\
\text { permeabilidade e, assim, } \\
\text { evitam tamponamento } \\
\text { cardíaco no pós-operatório } \\
\text { de cirurgia cardíaca? A } \\
\text { ordenha manual ou } \\
\text { mecânica está associada com } \\
\text { conseqüências clínicas } \\
\text { negativas? }\end{array}$ & $\begin{array}{l}\text { Estudo } \\
\text { experimental } \\
\text { controlado }\end{array}$ & $\begin{array}{l}\text { Manipulação de dreno de tórax } \\
\text { não mostra qualquer benefício } \\
\text { evidente em aumentar a } \\
\text { permeabilidade do dreno. Não } \\
\text { foram encontradas diferenças } \\
\text { significativas na drenagem } \\
\text { mediastinal total. Não houve } \\
\text { diferença na incidência de } \\
\text { tamponamento entre a ordenha } \\
\text { manual, ordenha com pinça, ou } \\
\text { nenhum ordenha. Nenhum } \\
\text { protocolo universal para } \\
\text { manipulação de dreno de tórax } \\
\text { foi usado. A prática ideal é } \\
\text { colocar o tubo horizontalmente } \\
\text { na cama ou cadeira antes de } \\
\text { cair verticalmente no frasco de } \\
\text { drenagem. }\end{array}$ & $\begin{array}{l}\text { Não houve provas sobre a } \\
\text { eficácia ou benefício na } \\
\text { manipulação de dreno torácico. } \\
\text { Nenhuma estratégia de } \\
\text { manipulação de dreno foi } \\
\text { associada com maior drenagem } \\
\text { mediastinal ou taxas de } \\
\text { oclusão. Se a avaliação } \\
\text { cuidadosa sugere que alguma } \\
\text { manipulação do tubo seja } \\
\text { necessária, opinião de } \\
\text { especialistas } \\
\text { contemporâneosrecomenda } \\
\text { suaves compressões e } \\
\text { liberação de pequenos } \\
\text { segmentos dos tubos de drenos } \\
\text { entre os dedos (ordenha } \\
\text { manual) em vez de ordenha } \\
\text { mecânica (com pinça). }\end{array}$ \\
\hline
\end{tabular}


ISSN 2179-6750

\begin{tabular}{|c|c|c|c|c|}
\hline $\begin{array}{l}\text { Managing a Chest Tube } \\
\text { and Drainage System. } \\
\text { Durai et al. } 2010 .\end{array}$ & $\begin{array}{l}\text { Fornecer informações para os } \\
\text { enfermeiros sobre os drenos } \\
\text { torácicos e sua gestão }\end{array}$ & $\begin{array}{l}\text { Pesquisa } \\
\text { Descritiva. }\end{array}$ & $\begin{array}{l}\text { Ordenha de dreno torácico } \\
\text { ocluído por coágulos não } \\
\text { parece ser recomendada porque } \\
\text { pode aumentar a pressão } \\
\text { negativa na cavidade } \\
\text { intratorácica, o que poderia } \\
\text { danificar o tecido pulmonar. }\end{array}$ & $\begin{array}{l}\text { Todos os enfermeiros que } \\
\text { cuidam de pacientes com } \\
\text { drenos torácicos devem ser } \\
\text { informados sobre o } \\
\text { gerenciamento de drenos } \\
\text { torácicos. }\end{array}$ \\
\hline $\begin{array}{l}\text { Nursing Management of } \\
\text { Chest Drains. } \\
\text { Maggie, } 2009 .\end{array}$ & $\begin{array}{l}\text { Análise da assistência de } \\
\text { enfermagem atual e gestão de } \\
\text { drenos torácicos. }\end{array}$ & $\begin{array}{l}\text { Não- } \\
\text { experimental, } \\
\text { Descritivo. }\end{array}$ & $\begin{array}{l}\text { Grandes variações de prática } \\
\text { têm sido observadas e são } \\
\text { baseadas em políticas locais e } \\
\text { preferências individuais em vez } \\
\text { de baseadas em evidências ou } \\
\text { protocolos. A drenagem pode } \\
\text { ser impedida por problemas no } \\
\text { sistema como tubos excessivos, } \\
\text { dobrados ou bloqueados. A } \\
\text { tubulação deve ser levantada } \\
\text { regularmente para drenar o } \\
\text { fluido para o frasco de } \\
\text { drenagem. }\end{array}$ & $\begin{array}{l}\text { Uma compreensão } \\
\text { abrangente sobre o sistema } \\
\text { de drenagem de tórax e } \\
\text { questões relacionadas seria } \\
\text { importante. Os efeitos da } \\
\text { compressão, ordenha manual } \\
\text { ou com pinça são } \\
\text { controversos e não são } \\
\text { normalmente aconselhados. }\end{array}$ \\
\hline $\begin{array}{l}\text { Troubleshooting Chest } \\
\text { Tubes. } \\
\text { Matters, } 2011 .\end{array}$ & $\begin{array}{l}\text { Educação continuada na } \\
\text { gestão de drenos da equipe } \\
\text { de enfermagem. }\end{array}$ & $\begin{array}{l}\text { Não- } \\
\text { experimental, } \\
\text { Descritivo. }\end{array}$ & $\begin{array}{l}\text { As evidências atuais } \\
\text { relacionadas a rotina da } \\
\text { ordenha de drenos torácicos } \\
\text { afirmam que esta prática não é } \\
\text { indicada por aumentar a } \\
\text { pressão intratorácica. }\end{array}$ & $\begin{array}{l}\text { O aumento das pressões } \\
\text { intratorácicas pode conter o } \\
\text { tecido pulmonar nas paredes } \\
\text { dos drenos de tórax } \\
\text { ocasionando hemorragia e } \\
\text { prejudica a função } \\
\text { ventricular esquerda. }\end{array}$ \\
\hline
\end{tabular}

\section{O Sistema de Drenagem}

O sistema de drenagem torácica deve caracterizar-se por ser unidirecional, fechado e aspirativo. Unidirecional porque deve funcionar num só sentido, permitindo a saída de coleções de modo a que elas não voltem a entrar, sendo este processo facilitado pela pressão negativa intrapleural; fechado por não permitir a entrada de ar no sistema de drenagem, e aspirativo por ter a possibilidade de ser conectada a um sistema de aspiração, mantendo-se assim, uma pressão negativa constante que facilite a extração das coleções intrapleurais ${ }^{13,14}$.

Após a realização de cirurgias cardíacas geralmente faz-se necessário o uso de drenos torácicos de inserção pleural ou mediastinal, ou ambos, a fim de reduzir o conteúdo de sangue e líquido acumulado nas cavidades pleurais e mediastinais. Para a drenagem mediastinal, o tubo pode ser inserido no pericárdio ou na região infracardíaca, longitudinal e anterior ao coração enquanto que a drenagem pleural é utilizada especialmente quando há dissecção da mamária para o enxerto ou acometimento pleural ${ }^{3}$.

Os drenos torácicos como características ideais precisam ser tubulares e multiperfurados, para proporcionar maior superfície de drenagem e menor chance de obstrução; siliconizados pela flexibilidade e dificuldade na aderência de coágulos; possuir consistência firme, com menor chance de colapsar e de formar coágulos. Os drenos precisam ter marcas radiopacas, objetivando estimar a quantidade de tubo que foi introduzida dentro do espaço pleural. Os drenos rígidos são evitados por 
ISSN 2179-6750

provocam dor e possibilidade de lesionar os pulmões ${ }^{12}$

A composição dos sistema de drenagem se dá por frasco coletor, tubo de drenagem e selo d'água que impede a entrada de ar na cavidade torácica. O frasco, de vidro ou de plástico transparente é graduado permitindo o controle do volume drenado. As conexões e o respiro devem ser de calibres adequados. O mecanismo que funciona como válvula no sistema de drenagem é o nível do líquido, que deve cobrir dois cetímetros distais do tubo do frasco de selo d'água, caso o tubo esteja mergulhado mais que dois centímetros a drenagem aérea acaba sendo prejudicada porque aumenta a resistência ao fluxo de drenagem ${ }^{12,14}$.

Para aumentar a velocidade de remoção, em algumas situações, utiliza-se um sistema de aspiração negativa contínua junto ao sistema coletor, que possui uma câmara de transmissão de alta pressão, regulável por meio de uma coluna d'água submersa, ligada a um sistema de vácuo ${ }^{3}$. Esse sistema permite aspirações suaves de $20 \mathrm{~cm}$ de água e raramente são precisas aspirações superiores. O manuseio de alta pressão deve ser delicado e em poucas ocasiões ela será necessária, por isso, é muito clara a necessidade de usar baixas aspirações ${ }^{11}$. Possuem vários tamanhos, possui um diâmentro de $6 \mathrm{Ch}$ até $40 \mathrm{Ch}$ (cada 3 medições Charriere corresponde a 1mm). As conexões e tubos de conexões permitem unir o dreno ao selo d'água, podendo ser de borracha, com 1.5 a $2 \mathrm{~m}$ de comprimento. A medida excessiva do comprimento dessas extensões pode favorecer a formação de alças, estas devem ser evitadas pois dificultam a drenagem.

$\mathrm{Na}$ drenagem subaquática normalmente são utilizados frascos com capacidade superior a 5 litros a altura de 20 a $25 \mathrm{~cm}$. É possível utilizar até 3 frascos para um sistema de drenagem sob aspiração, com um coletor isolado ao produto da drenagem, ou apenas um frasco, com líquido impedindo o colapso pulmonar por uma haste imersa no mínimo $2 \mathrm{~cm}$ da água ${ }^{11}$. A câmara de selo d'água permite que exista apenas uma forma de movimento, sendo que ar e líquido podem escapar da cavidade pleural, mas não podem fluir na direção inversa. Esta câmara também impede a entrada de ar atmosférico na cavidade torácica e não pode ser esvaziada a não ser que o recipiente esteja cheio de drenagem ${ }^{15}, 16$.

Os frascos para drenagem simples podem ter uma haste imersa e um ou dois orifícios laterais na tampa em contato com o ar ambiente. Ao se utilizar um conjunto com dois frascos, necessariamente um deles funcionará como válvula unidirecional, este controlará a quantidade de sucção aplicada ao espaço pleural, por uma fonte de aspiração contínua, que depende da diferença de coluna entre os dois frascos. O sistema de três frascos requer uma fonte geradora de sucção contínua. O primeiro frasco coletor não interfere com o sistema de drenagem aspirativa, o segundo atua como válvula unididirecional e o terceiro controla a sucção exercida sobre o sistema. A fonte 
ISSN 2179-6750

geradora de sucção estará condicionada à diferença de profundidade das hastes submersas $(2-20=18$ $\mathrm{cm} \mathrm{H} 2 \mathrm{O})^{12}$. A pressão aplicada ao respiro pelo selo d'água anula a pressão atmosférica e produz pressão negativa no frasco facilitando a drenagem ${ }^{15}$.

O acúmulo de coágulos dentro dos drenos acarreta preocupação entre os cirurgiões cardiotorácicos, e muitos serviços tem rotina de manuseios destes drenos com o intuito de previnir a oclusão ${ }^{10}$.

\section{As Falhas na Drenagem Torácica}

As principais falhas que podem ocorrer na drenagem torácica estão relacionados a obstrução do tubo por coágulos ou fibrina, clampleamento inapropriado, dobras por comprimento excessivo da extensão, posicionamento, fixação e conexão inadequadas do dreno, altura inapropriada do selo dágua, posicionamento indevido do frasco coletor, obliteração do respiro, negligência na verificação de oscilação do selo d'água ${ }^{12}$.

Para manter a permeabilidade do circuito é preciso que se matenha o tubo sem angulações, evitar que tenha rotação do tubo, manter os sistemas de drenagem abaixo do local de inserção do dreno, "mugir", ou seja, realizar movimentos de pequenos apertos da tubulação, se necessário, na direção do frasco. Esta é, no entanto, uma ação que deve ser executada quando está em risco a obstrução do dreno, e não por rotina, uma vez que pode causar lesões, pelas baixas pressões que provoca $^{8} \cdot$ Para evitar possíveis complicações no sistema de drenagem como dobras e obstruções, os cuidados devem ser constantes e cuidadosamente verificados. A permeabilidade do sistema de drenagem pode ser reestabelecida através da ordenha criteriosa do equipo, tomando o cuidado de não haver desconexão do mesmo, pois o aumento brusco da pressão negativa dentro do tórax pode prejudicar a reparação cirúrgica ou deflagrar uma arritmia ${ }^{9}$.

Deve-se atentar para manutenção do tubo sem angulações, evitar que haja rotação do mesmo, ou seja, que eles fiquem torcidos e o cuidado para que o sistema de drenagem mantenha-se sempre abaixo do local de inserção do drenos, o enrolamento excessivo da tubulação também deve ser evitado ${ }^{17}$.

A oclusão dos tubos torácicos pode ser grave e podem levar a episódios de pneumatórax repetidos. O sistema de drenagem deve ser inspecionado regularmente e realiza-se a ordenha dos drenos objetivando desalojar coágulos temporariamente e aumentar a sucção interna mantendo a permeabilidade do sistema de drenagem ${ }^{11}$. As técnicas incluem a ordenha manual ou milking, ordenha com pinça ou stripping, dobraduras e percussão que podem ser aplicadas aos tubos ${ }^{11,13}$.

A incidência de tamponamento é baixa, independentemente do protocolo de manipulação de 94 
ISSN 2179-6750

drenos executado e a drenagem visível na tubulação não causou falta de permeabilidade. Portanto, nem sempre é necessário manipular o dreno torácico quando a drenagem sanguínea é identificada 14.

Em estudo randomizado controlado comparando ordenha manual e com pinça com um grupo controle que não tinha nenhuma manipulação, não houve diferenças significativas entre os três grupos em volume de drenagem média total e na incidência de arritmias ou frequência cardíaca média, mostrando que os tubos não manipulados parecem não ter conseqüências adversas clínicas. Além disso, não houve incidências de oclusão do tubo em qualquer um dos três grupos, o que implica que os drenos, deixados livre de manipulação, foram aceitáveis em termos de eliminação de coágulo na maioria dos pacientes ${ }^{15}$.

Manipulação de drenos de tórax não mostra qualquer benefício evidente para aumentar a permeabilidade de drenos. Não foi encontrada uma forte evidência para a necessidade de manipular rotineiramente drenos para auxiliar na drenagem mediastinal após cirurgia cardíaca ${ }^{9}$.

Um especialista da Associação Americana de Cuidados Críticos, também concluiu com base nas evidências disponíveis que as rotinas de ordenhas striping ou milking na tubulação também não é recomendada e confirmou a falta de provas para apoiar essa prática ${ }^{7}$.

Em estudo de revisão sistemática comparando diferentes métodos de manipulações dos drenos (níveis de aspiração, ordenha, ordenha com pinça, dobraduras e batidas) para manter a permeabilidade dos drenos na prevenção de tamponamento cardíaco após a cirurgia cardíaca, não foi encontrado nenhuma evidência para suportar a eficácia de um método de manipulação sobre o outro após a cirurgia cardíaca e nem se obteve provas para apoiar a necessidade de manipular os drenos de tórax de qualquer forma ${ }^{5}$.

\section{A Ordenha dos drenos}

A presença de drenos torácicos tem uma tendência a tornar-se bloqueados por coágulos. $\mathrm{O}$ principal sinal de bloqueio de drenos é a falha da flutuação do selo d'água dentro dos frascos de drenagem com o ciclo respiratório ou com a tosse ${ }^{18}$.

Tubos torácicos de pequeno calibre podem tornar-se bloqueados por coágulos sanguíneos e de fibrina. A oclusão pode ser grave e podem levar a episódios de pneumatórax repetidos. O sistema de drenagem deve ser inspecionado regularmente e realiza-se a ordenha dos drenos objetivando desalojar coágulos temporariamente e aumentar a sucção interna mantendo a permeabilidade do sistema de drenagem ${ }^{12}$. As técnicas incluem a ordenha manual ou milking, ordenha com pinça ou stripping, dobraduras e percussão que podem ser aplicadas aos tubos ${ }^{16}$. 
ISSN 2179-6750

Uma técnica de ordenha para desobstrução do sistema consiste nos seguintes passos: Para ordenhar, segurar o dreno próximo ao tórax e ordenhá-lo entre os dedos e a palma da mão; mover a outra mão para a próxima porção do dreno, soltando a primeira mão e movendo para a próxima porção do dreno, continuando em direção ao frasco de drenagem. Para comprimir colocar lubrificante nos dedos de uma mão e apertar com força o dreno de tórax com os dedos da outra mão. Apertar o dreno abaixo da porção comprimida, com os dedos lubrificados e deslizar os dedos para baixo em direção aos sistema de drenagem. Soltar lentamente o pressionamento dos dedos não lubrificados e então fazer o mesmo com os dedos lubrificados ${ }^{16,17}$.

O uso de "clamp" ou "braçadeira"

Drenos torácicos não devem ser clampeados, exceto quando requisitados, nas seguintes ocasiões: saber se os drenos já podem ser retirados, na determinação da origem de algum vazamento de ar ou na desconexão do sistema, como na troca de frascos coletores, devendo em seguida ser desclampeado ${ }^{18,19}$. O uso indiscriminado da braçadeira é muito sério entre os erros de manejos com drenos torácicos. No entanto, por vício de uso ou por falta de informação, muitos serviços continuam a usar rotineiramente este dispositivo, para mobilização de transportes, deambulação ou saída do leito. O seu uso pode ter consequências agudas catastróficas, como pneumatórax hipertensivo, parada cardíaca e hematórax retido ${ }^{10}$.

\section{Controle da drenagem}

Normalmente nas primeiras horas a consistência do conteúdo drenado será hemática e progressivamente passará a mais serosa, diminuindo também de forma progressiva sua quantidade, sendo no início mais abundante. A medida exata da drenagem é essencial, esta não deverá exceder $200 \mathrm{ml} / \mathrm{h}$ durante as primeiras 4 a 6 horas $^{6}$. Na cirurgia cardíaca um sangramento considerado excessivo é aquele com mais de $3 \mathrm{ml} / \mathrm{kg} / \mathrm{h}$ durante as três primeiras horas e mais de $1,5 \mathrm{ml} / \mathrm{kg} / \mathrm{h}$ a partir da terceira hora. Se complicações estiverem ausentes e não houver sangramento excessivo, os drenos são geralmente retirados na manhã do segundo dia de pós-operatório ${ }^{4}$.

Deve ser anotado rigorosamente qual o volume drenado por unidade de tempo, o aspecto do líquido drenado, a existência de fístula aérea e presença de borbulhamento no frasco. As conexões e as extensões devem ser verificadas quanto à presença de coágulos, principalmente os pontos de conexões, pois estes são os mais propensos a reter coágulos². 
ISSN 2179-6750

As evidências científicas

Não há estudos suficientes que comparem diferentes métodos de manipulação de drenos torácicos para apoiar ou não a eficácia relativa dos vários métodos para prevenir tamponamento cardíaco. Nenhuma evidência de fato que seja clara e universal foi encontrada sobre a necessidade de manipulação de drenos como um todo. Os autores ainda citam que a objetividade e especificação nas definições dos tipos de manipulação geralmente são confusas e controversas ${ }^{5}$.

Vários estudos relataram não haver diferença significativa na produção de drenagem mediastinal quando os drenos foram rotineiramente ordenhados, despojados, ou não tinham nenhuma manipulação, os drenos mantiveram-se permeáveis. Portanto, parece que a milking ou a stripping de drenos torácicos como rotina básica devem ser evitados ${ }^{7}$. A incidencia de tamponamento é baixa, independentemente do protocolo de manipulação de drenos executado e a drenagem visível na tubulação não causou falta de permeabilidade. Portanto, nem sempre é necessário manipular o dreno torácico quando a drenagem sanguínea é identificada ${ }^{8}$.

Em um estudo randomizado controlado comparando ordenha manual e com pinça com um grupo controle que não tinha nenhuma manipulação não se encontrou diferenças significativas entre os três grupos em volume de drenagem média total e na incidência de arritmias ou frequência cardíaca média, mostrando que os tubos não manipulados parecem não ter conseqüências adversas clínicas. Além disso, não houve incidência de oclusão do tubo em qualquer um dos três grupos, o que implica que os drenos, deixados livre de manipulação, foram aceitáveis em termos de eliminação de coágulo na maioria dos pacientes. Manipulação de drenos de tórax não mostra qualquer benefício evidente para aumentar a permeabilidade de drenos. Não foi encontrada uma forte evidência para a necessidade de manipular rotineiramente drenos no auxílio na drenagem mediastinal após cirurgia cardíaca ${ }^{9}$.

Um especialista da Associação Americana de Cuidados Críticos, também concluiu com base nas evidências disponíveis que as rotinas de ordenhas striping ou milking na tubulação também não é recomendada e confirmou a falta de provas para apoiar essa prática ${ }^{7}$.

Em estudo de revisão sistemática comparando diferentes métodos de manipulações dos drenos (níveis de aspiração, ordenha, ordenha com pinça, dobraduras e batidas) para manter a permeabilidade dos drenos na prevenção de tamponamento cardíaco após a cirurgia cardíaca, não foi encontrado nenhuma evidência para suportar a eficácia de um método de manipulação sobre o outro após a cirurgia cardíaca e nem se obteve provas para apoiar a necessidade de manipular os drenos de tórax de qualquer forma. Não há estudos suficientes que comparem diferentes métodos de manipulação de drenos torácicos para apoiar ou não a eficácia relativa dos vários métodos para 
ISSN 2179-6750

prevenir tamponamento cardíaco. Nenhuma evidência de fato que seja clara e universal foi encontrada sobre a necessidade de manipulação de drenos como um todo. Os autores ainda citam que a objetividade e especificação nas definições dos tipos de manipulação geralmente são confusas e controversas entre os autores 5 .

Em uma série de casos, prospectivos, examinando as pressões associadas com ordenha de dreno de tórax. Os autores relatam complicações, como o aprisionamento de tecidos sendo relatados com pressões pequenas como $-15 \mathrm{~cm} \mathrm{H} 2 \mathrm{O}$, e que as pressões exercidas por ordenha, portanto, têm o potencial para causar lesão tecidual ${ }^{7}$.

A ordenha de drenos pode aumentar significativamente as pressões negativas, causando danos, como o sangramento excessivo, disfunção ventricular esquerda, prejudicando a recuperação do paciente no pós operatório ${ }^{9}$.

Manobras de ordenha como aquelas com auxílio da utilização de pinças - stripping, criam um vácuo dentro da tubulação, gerando pressões intratorácicas negativas muito elevadas (- 100 a $400 \mathrm{~cm}$ de $\mathrm{H}_{2} \mathrm{O}$ ), podendo causar traumas nos tecidos pulmonares, hemorragias e comprometer ainda mais as condições pulmonares. Dado o risco de danos e da escassez de evidências quanto ao seu benefício, essas manobras não devem ser executadas ${ }^{15}$.

A oclusão temporária através do "clamp" ou braçadeira pode ter consequências imediatas catastróficas, como pneumatórax hipertensivo, balanço mediastinal, parada cardíaca e hematórax retido. Muitas vezes opta-se por não retirar as braçadeiras, e assim clampeamentos indevidos no momento do banho, do transporte do paciente ou na troca do leito, podem eventualmente ocorrer ${ }^{10}$.

O acúmulo de drenagem pode ser impedida por enrolamento excessivo, angulações e tubos torcidos ou bloqueados ${ }^{17}$. Entretanto, se após cuidadosa avaliação alguma manipulação for necessária para manter a permeabilidade do dreno de tórax, esta deve ser realizada apenas quando um coágulo tornar-se visível ou quando estiver obstruindo a drenagem. Neste caso, recomendam-se suaves compressões e liberação de pequenos segmentos dos tubos torácicos entre os dedos, milking em vez de stripping. O que dá suporte no quesito manutenção da permeabilidade dos drenos é a prevenção de angulações nas tubulações por impedir a drenagem a partir do espaço pleural com potencial para aumentar a pressão torácica. A tubulação em excesso deve ser enrolada ou mantida paralela ao chão, horizontalmente na cama ou cadeira, antes de cair verticalmente para o dispositivo de drenagem ${ }^{7}$.

A drenagem no espaço mediastinal é auxiliada pela sucção e posicionamento apropriado das tubulações de drenagem, incluindo a prevenção de dobramento dos tubos. Evidências a partir de dois estudos laboratoriais demonstraram que a drenagem do espaço pleural é impedida quando a 
ISSN 2179-6750

tubulação estiver enrolada. Nestes estudos a posição do tubo reta e em espiral foram ótimas para a drenagem de fluídos, entretanto, para formação de coágulos nos drenos pode-se colocar algumas compressas embebidas com álcool ao redor das inserções dos drenos e ordenhá-los ${ }^{1}$.

O levantamento constante das tubulações a cada 15 minutos é indicado, pois a gravidade ajuda o sangue ou qualquer material viscoso drenar com mais facilidade para dentro do frasco ${ }^{13}$. Se um coágulo é visto na tubulação, comprime-se o tubo levemente entre os dedos levando-o na direção do frasco da drenagem ${ }^{15,19}$.

Em um estudo sobre a influência do uso do "clamp" ou braçadeira no acúmulo de coágulos em drenos pleurais e tubulares obervou-se uma desvantagem do sistema de braçadeira para oclusão temporária do sistema de drenagem, ocorrendo maior acúmulo de coágulos sanguíneos em relação àqueles em que a braçadeira foi retirada ${ }^{10}$.

O efluxo por meio do dreno é potencializado quando o paciente se mobiliza no leito, levanta-se e deambula. Daí a importância de manter os sistemas sem clampeamento nesses casos. No sistema de vasos comunicantes, o fluxo se estabelece no sentido do compartimento mais elevado para o inferior, motivo pelo qual o frasco deve permanecer em desnível inferior ao tórax do paciente. Considerando-se qua a máxima pressão subatmosférica é de $54 \mathrm{~cm}$ de $\mathrm{H}_{2} \mathrm{O}$ durante inspiração profunda e que o sistema de dreno mede cerca de $200 \mathrm{~cm}$, há uma margem de segurança pressórica de cerca de $150 \mathrm{~cm}$ de $\mathrm{H}_{2} \mathrm{O}$, mesmo quando o dreno é temporariamente mantido no mesmo nível torácico. No caso de situações de transferências de setor, reforça-se a ausência de necessidade de oclusão do tubo ${ }^{20}$.

\section{Conclusões}

Para a manutenção da permeabilidade dos drenos, recomenda-se a prevenção de angulações, enrolamento excessivo, tubos torcidos e dobramentos. O levantamento das tubulações de quinze em quinze minutos, evitar o excesso ou prolongamento das tubulações e manter os drenos paralelamente ao chão antes de cair horizontalmente no frasco coletor são práticas indicadas.

Apesar dos sistemas de drenagem subaquáticas serem de origem secular, ainda existem contradições quanto ao manejo dos pacientes que necessitam desse tipo de dreno. Além de equipamentos e material adequado aos profissionais que manejam esses cuidados, o sucesso terapêutico é diretamente vinculado a qualificação e treinamento continuado adequados.

A presente revisão buscou realizar um resumo sobre a evidência científica atual relacionada as seguinstes questões: a ordenha é indicada como prática rotineira? Quais são os benefícios e/ou malefícios existentes? O que esta sendo indicado na prática atual para manutenção da 
ISSN 2179-6750

permeabilidade dos drenos? A insuficiência de evidências baseadas sobre essas questões cria uma incerteza geral quanto ao atendimento dos pacientes com drenos torácicos. As complicações são prováveis de acontecer, principalmente, se os drenos forem manipulados por profissionais erroneamente qualificados ou com habilidades inadequadas. O importante é que estes cuidados sejam embasados em evidências científicas adequadas para prevenir prováveis complicações e promover segurança aos pacientes, pois estes cuidados envolvem tanto conhecimentos fisiológicos quanto anatômicos complexos.

Observou-se que a maior parte da literatura disponível sobre gestão de drenos, especificamente no que diz respeito às questões norteadoras abordadas neste trabalho são baseadas em opiniões de especialistas e revisões de literatura, necessitando assim, de estudos experimentais para apoiar estas práticas.

A ordenha de drenos, não deve ser recomendada como prática rotineira ou com objetivo de auxiliar na drenagem dos fluídos no pós-operatório de cirurgica cardíaca. A maioria dos autores indicam que a ordenha deve ser realizada somente quando um coágulo estiver evidente, realizandoa de maneira delicada ou com suaves apertos.

Outro achado importante foi relacionado ao uso do "clamp" para ocluir temporariamente durante banhos, transporte etc. Alguns estudos realizados acreditam que este tipo de atividade rotineira pode ajudar no acúmulo de coágulos sanguíneos, além de outras complicações clínicas como pneumatórax hipertensivo, parada cardíaca, balanço mediastinal. Os achados reforçam a ausência de necessidade de oclusão dos tubos. No que diz respeito a manutenção da permeabilidade dos drenos, algumas recomendações como prevenção de angulações, enrolamento excessivo, tubos torcidos e dobramentos foram enfatizadas por diversos autores. O levantamento das tubulações de 15 em 15 minutos, o excesso da tubulação a ser enrolado ou mantido paralelamente ao chão antes de cair horizontalmente no frasco coletor são práticas indicadas pelos autores.

Sumarizando a pergunta de pesquisa em relação a manipulação de drenos não foi encontrada nenhuma evidência que apoie essa conduta, ao contrário, as manipulações agressivas, como por exemplo, a ordenha com auxílio de pinças, podem ocasionar o aumento da pressões negativas intratorácicas e acredita-se que o aumento dessas pressões podem vir a causar alguns danos como, aumento do sangramento, disfunção ventricular esquerda.

Acredita-se que as evidências encontradas neste estudo sejam de grande relevância para a prática clínica, reforçando-se a necessidade de ensaios clínicos bem delineados e/ou relatórios de comitês de especialistas como medidas de avaliação e qualidade da evidência na manipulação de drenos torácicos. 


\section{Referências}

1. Gil AL, Carmona SJV, Montañes A F J. Cuidados de Enfermería Del drenaje mediastínico em cirugía extracorpórea. Enfermería Integral. 2007;3 -7.

2. Soares GMT, Ferreira DCS, Gonçalves MPC, Alves TGS, David FL, Henriques KMC. Prevalência das Principais Complicações Pós-Operatórias em Cirurgias Cardíacas Rev Bras Cardiol 2011; 24(3):139-146.

3. De Santana LL, Leal PP, Gimenes AC, Junior GC, De Fonseca JHP. Drenagem torácica na mecânica e função autonômica no pós-operatório de cirurgia cardíaca. 2008; 7(4): 335-340.

4. Parra AV, Renée C, Amorim C, Saskia E, Wigman, L M. Retirada de dreno torácico em pósoperatório de cirurgia cardíaca. Arq Ciênc Saúde. 2005; 12(2): 116-119.

5. Wallen J, Morrison A, Gillies D, O'Riordan E, Bridge C, Stoddart F. Mediastinal chest drain clearance for cardiac surgery (review). Cochrane Database Syst Rev. Review. Update in: Cochrane Database Syst Rev. 2009.

6. Smeltzer SC, Bare BG. Brunner e Suddarth - Tratado de Enfermagem médico-cirúrgica. 11 ${ }^{\mathrm{a}}$ ed. Rio de Janeiro: Guanabara Koogan; 2009. vol. 2. p. 639-644.

7. Kirkwood P. Chest Tubes routinelly milked, stripped, or suctioned to maintain patency? Do staff nurses irrigate chest tubes with small amounts of isiotonic sodium chloride tonbreak up clots? [Ask the Expert] Critical Care Nurses. 2002; 22: 70-72. Downloaded from ccn.aacnjournauls.org by guest on March 21, 2012.

8. Charnock YP, Evans D. Nursing management of chest drains: a systemic review. Australian Critical Care 2001:14 (4), 156-160.

9. Margo AH. To Strip or Not to Strip? Physiological Effects of Chest Tube Manipulation. American Journ Critical Care. 2007; 16: 609-612. Downloaded from ajcc.aacnjournls.org by guest on November 23, 2011.

10. Lima AG, Rocha ERF, Seabra JCT, Mussi RK, Dos Santos JG, Toro IFC. A Influência do Uso Do "Clamp” ou Braçadeira no Acúmulo de Coágulos em Drenos Pleurais Tubulares. RevColBras Cir. 2008; 35(2):079-082.

11. Rumbero JC. Drenagem torácica. Espanha: Hospital Universitário de Cruces. 2002, 4-16.

12. Kusahara DM, Chanes DC, Harada MJCS. Boas Práticas - Drenos de Tórax [artigo de atualização]. Conselho Regional de São Paulo. 2011; 1-15.

13. Lehwaldt D, Timmins F. Nurses' knowledge of chest drain care: an exploratory descriptive survey. British Association of Critical Care Nurses, Nursing in Critical Care. 2005; 10(4): 192-199. 
ISSN 2179-6750

14. Sahns SA, Jantz, MA. Tube thoracostomy. In: ROSE, B. D.; WALTHAM, M. A. (Ed.). UpToDate 15.2. Massachusetts: UpToDate, 2007

15. Puchalski LP. Should Neonatal Chest Tubes Be "Stripped"? Medscape Nurses [Ask The Experts] 2009 [postadoem 12/31/09].

16. Durai R, Hoque H, Davies TW. Managing a Chest Tube and Drainage System. AORN Journal 2010, 91(2): 275-283.

17. Maggie L. Nursing Management of Chest Drains. Hong Kong Respiratory Medicine. 2009. Las Updated on Thursday, 18 February 2010.

18. Chung DC. Chest Drain: FAQ. The Chinese University of Hong Kong 2008. Downloaded from http://medicine-online.com.br. By guest on November 23, 2011.

19. Matters M. Troubleshooting Chest Tubes. Advance for Nurses. 2011. Acessed 21/02/2012. Available:http://nursing.advanceweb.com/continuing-education/ce-articles/troubleshootingchest-tubes.aspx.

20. Nichida G, Sarrão BD, Colferai RD, Tenório GOS, Bandeira COP. Cuidados com o sistema de drenagem torácica em adultos internados no Hospital Universitário Regional de Maringá, Estado do Paraná, Brasil. Acta Scentiarum. Health Sciences 2011; 33:2. 